\title{
Experimental and Numerical Analysis of Normal and Lateral High-Velocity Impacts on Carbon Fiber-Reinforced Polymer Laminates
}

\author{
T. Huang, ${ }^{1}$ Z. C. Liu, and Y. L. Wang
}

School of Mechanics, Civil Engineering and Architecture, Northwestern Polytechnical University, Xian, China

1 jiaogroup@163.com

This paper examines the effects of normal and lateral high-speed impacts on carbon fiber-reinforced polymer laminates. Experimental tests were conducted at varying velocities $(120-200 \mathrm{~m} / \mathrm{s})$, and the differing damage modes between normal and lateral impacts were analyzed. Dynamic finite element analysis was performed to simulate the damage process using the finite element software ABAQUS. The simulation shows a good correlation with the experimental results.

Keywords: carbon fiber-reinforced polymer (CFRP), high-speed impact, lateral impact, finite element analysis.

Introduction. Composite materials are popular in aviation and automotive industries due to their mechanical properties, such as high in-plane strength and stiffness with respect to destiny, and good shock absorption performance [1]. As a result, the percentage of composite materials in airframes, engines, and similar structures has been on the rise. The Boeing 787 DreamLiner comprises 50\% composite materials. Similarly, the F404 turbofan engine case and GE90 turbofan engine fan blades also contain a significant amount of composite materials. Composite materials are also popular in stealth aircraft production because they absorb microwaves. The B-2 stealth bomber and F-22 fighter have $35 \%$ and $40 \%$ composite materials, respectively [2].

Foreign object damage (FOD) is the impact damage to aircraft engines, airframes, and other structural components caused by foreign objects. Foreign objects include items such as stones, screws, or birds. The concept of FOD started with the U.S. Air Force in the 1950s [3] and has been an important facet of aviation research ever since. Engineers now build advanced aircraft with FOD factors in mind [3-14]. Globally, FOD causes a loss of approximately $\$ 13$ billion per year. Forty percent of turbofan engine renovations are caused by FOD [15].

Composite materials are widely used in aircrafts, and FOD resistance is critically important for aircraft design. Therefore, multiple studies have been conducted on FOD performance for aviation composite materials. In 1985, Cantwell and Morton [16] analyzed non-destructive detection techniques to explore the advantages and disadvantages of each method to detect impact damage on composite materials; in 1989, they conducted low- and high-velocity impact tests. These tests revealed that high-velocity impacts are not governed by specimen size, and that they are more detrimental to the composite structure than low-velocity impacts with the same impact energy [17, 18]. In 2003, Tanabe et al. [19] performed high-velocity impact tests for composite materials of different reinforcing fibers and different matrix materials. They found that the material properties of reinforcing fibers and matrixes strongly affect the impact resistance of composite materials. In 2005, Johnson and Pentecôte [20] used shell elements to conduct a numerical simulation of high-velocity impacts on a double-walled composite structure. In 2008, Hazell et al. [21, 22] determined the energy absorption of CFRPs by damage extension was constant for different highvelocity impacts. Appleby-Thomas et al. [23] conducted ice impact tests with CFRPs in 2011 to simulate hail storm impacts, studying the damage type and CAI strength. 
Shimamoto et al. [24] performed an impact test at low temperatures in 2012; they found that the stacking sequence is important to determine the damage type of a main space structure. In 2007, López-Puente et al. [25] conducted normal and oblique ballistic impact tests and numerical analysis on carbon/epoxy woven laminates to study the relation of the impact angle and damage area with different velocities. And in 2013, Pernas-Sánchez et al. [26] conducted the same test on carbon/epoxy tape laminates; they developed an empirical formula to calculate the damage area and residual velocity of the projectile at different impact angles.

This paper focuses on high-velocity normal impacts to composite materials. In an actual environment where the aircraft engine inlet size is $3-8 \mathrm{~m}$, the velocity of foreign objects is approximately $25 \mathrm{~m} / \mathrm{s}$. However, due to the high speed of rotating blades, the resulting impact velocity exceeds $200 \mathrm{~m} / \mathrm{s}$. Thus, blades are likely to suffer from lateral impacts. As previous studies have shown, composite laminates are not designed to bear lateral impact (impact normal to through-the-thickness direction), so there are few studies on ballistic lateral impact of CFRPs. This study presents experimental and numerical simulation results for this scenario, and compares the results with the normal-impact damage model.

1. Procedure. We conducted a high-velocity impact test for a CFRP laminate made by Beijing Aeronautical Manufacturing Technology Research Institute. The CFRP laminate possessed a T300 high-strength carbon fiber as reinforcing fiber and a QY8911 resin as matrix. The stacking sequence was $\left[(45 / 0 /-45 / 90)_{4} / 0\right]_{s}$. Figure 1 indicated the stacking angles. Its dimensions were $150 \mathrm{~mm}$ long, $45 \mathrm{~mm}$ wide, and approximately $5 \mathrm{~mm}$ thick. As shown in Fig. 2, the specimen was fastened by bolts at both ends by the frame plate and holder plate.

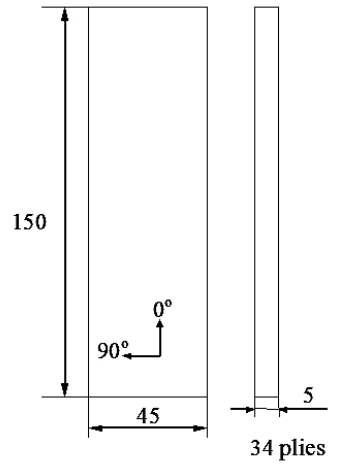

Fig. 1. Dimensions of the specimen.
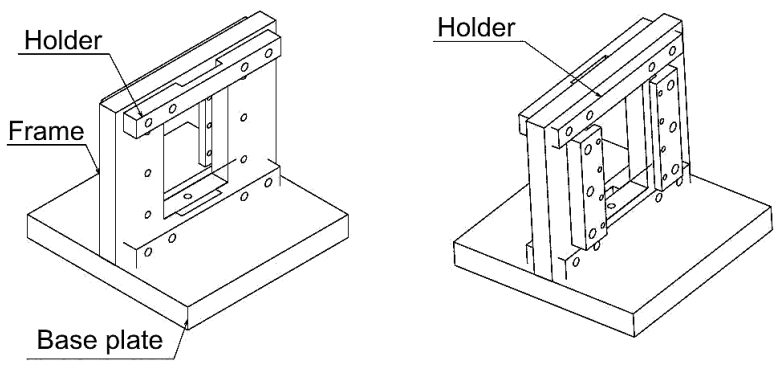

Figure 3 shows the ballistic impact testing machine created by the Ruijie Company. It was a compressed-air cannon comprised of a gas cylinder, an air tank, a launching valve, and a laser velocimeter. It used compressed gas to accelerate a spherical projectile. The bore was smooth, with a caliber of $6 \mathrm{~mm}$ and a maximum design speed of $200 \mathrm{~m} / \mathrm{s}$. The spherical projectile was made of bearing steel, was $6 \mathrm{~mm}$ in diameter, and weighed $0.85 \mathrm{~g}$.

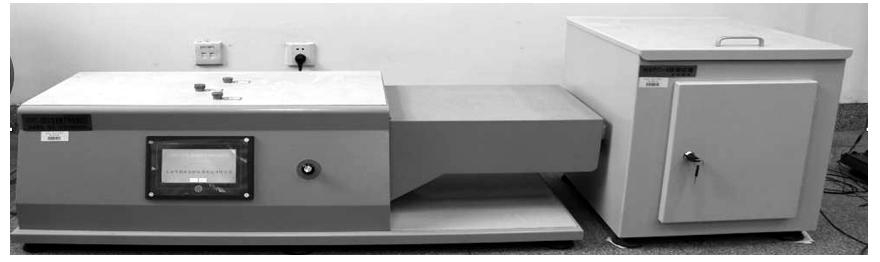

Fig. 3. Ballistic impact testing machine. 
Normal and lateral impact tests were performed at five different velocities: 200, 180, 160,140 , and $120 \mathrm{~m} / \mathrm{s}$. An HD camera recorded the surface impact damage, and a C-SAN recorded internal impact damage.

2. Results. Figure 4 displays typical surface damage for normal impacts. Figures 5 and 6 show lateral impact damage $(200 \mathrm{~m} / \mathrm{s}$ impact speed). No specimen was perforated at the maximum impact speed $(200 \mathrm{~m} / \mathrm{s})$. For the specimen that suffered the normal impact, the projectile collision generated a crater on the obverse surface. Cracks extended along the fiber direction out from the crater; there was no obvious damage on the reverse side. For the specimen that suffered the lateral impact, there was also a crater on the specimen's side. The impact was deeper than the normal-impact crater. There are protrusions on both surfaces with the matrix crack; the crack extended along the fiber direction out from the crater. The crack length was longer in the lateral impact than in the normal impact.

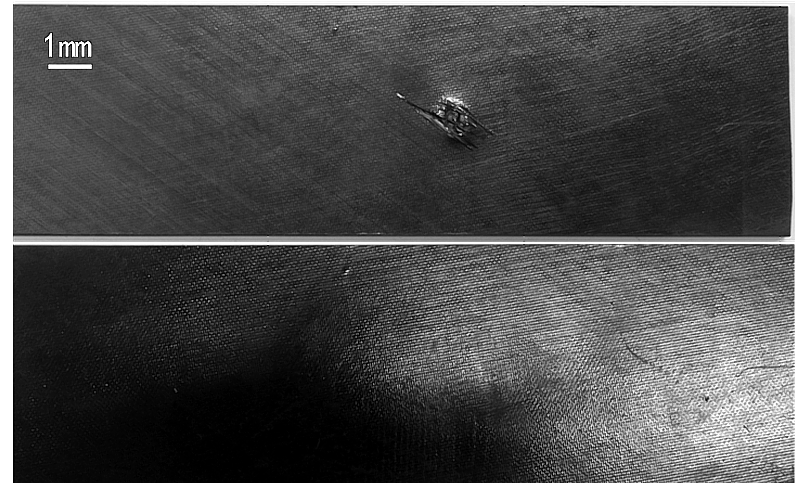

Fig. 4. Typical surface damage from a normal impact (up side and down side).

Fig. 5. Typical side damage from a lateral impact.
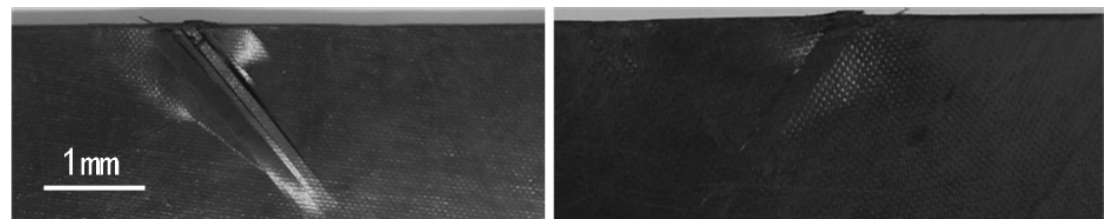

Fig. 6. Typical surface damage from a lateral impact (right side and left side).

Figure 7 shows C-SAN radiographs of the specimen that suffered the normal impact. Figure 8 shows C-SAN radiographs of the lateral-impact specimen. The impact velocities were $200,180,160,140$, and $120 \mathrm{~m} / \mathrm{s}$ from left to right. In Fig. 7, the shape of the damaged region was roughly circular and the damage sizes increased gradually along the thickness direction from top to bottom. In Fig. 8, the damaged region was semicircular, and symmetrical from top to bottom. The color of the damage area became deeper with increasing speed, which indicates that the damage area was closer to the surface at higher speeds.

The damage region for the normal impact was roughly circular, so formula (1) [27] was used to estimate its size; formula (2) was used to estimate the damage region of the lateral impact because it was semicircular. 


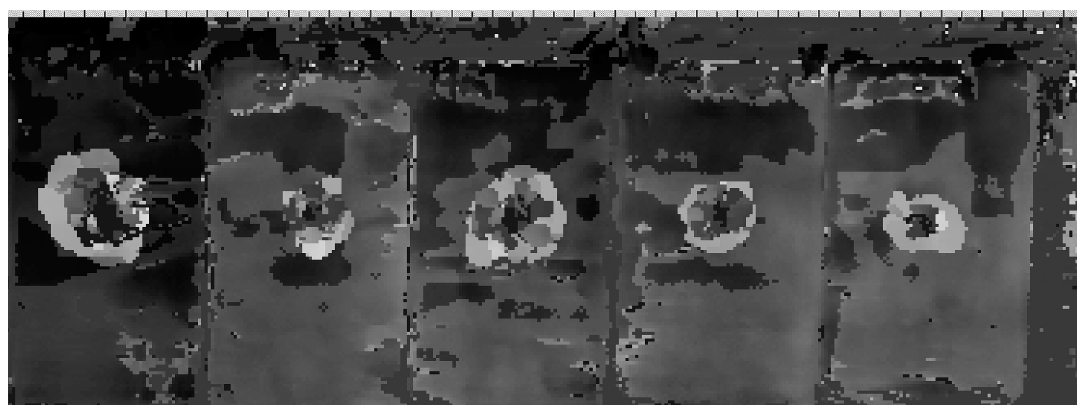

Fig. 7. C-SAN radiographs of a normal impact.

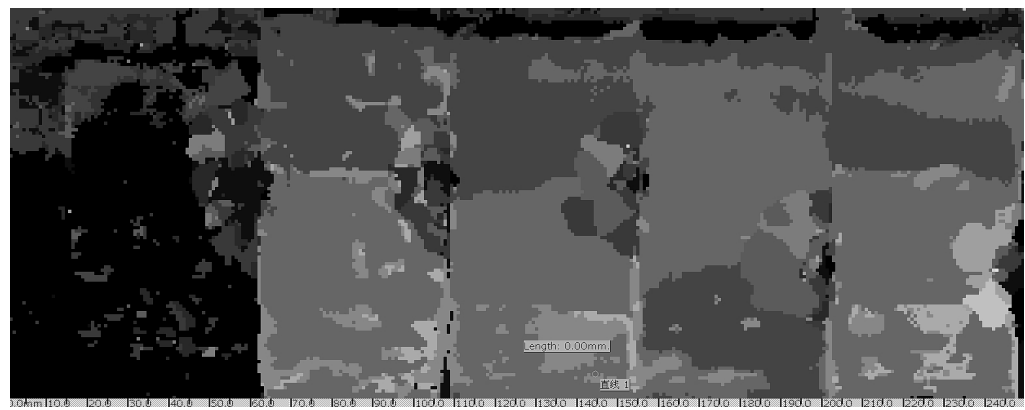

Fig. 8. C-SAN radiographs of a lateral impact.

$$
\begin{aligned}
& D_{a}=\frac{1}{4} \pi\left(l_{d}+w_{d}\right)^{2}, \\
& D_{a}=\frac{1}{8} \pi\left(l_{d}+w_{d}\right)^{2} .
\end{aligned}
$$

In both formulas, $l_{d}$ and $w_{d}$ are the maximum damage distance extending along the $0^{\circ}$ and $90^{\circ}$ directions, respectively, and $D_{a}$ is the projection area of delamination damage. The $l_{d}$ and $w_{d}$ quantities were measured from an electrical ruler on a C-Scan screen. (The unit of measure is $\mathrm{mm}^{2}$.)

Figure 9 shows that the damage size changes with speed for the two impact styles; the damage size for the normal impact is slightly larger than that of the lateral-impact.

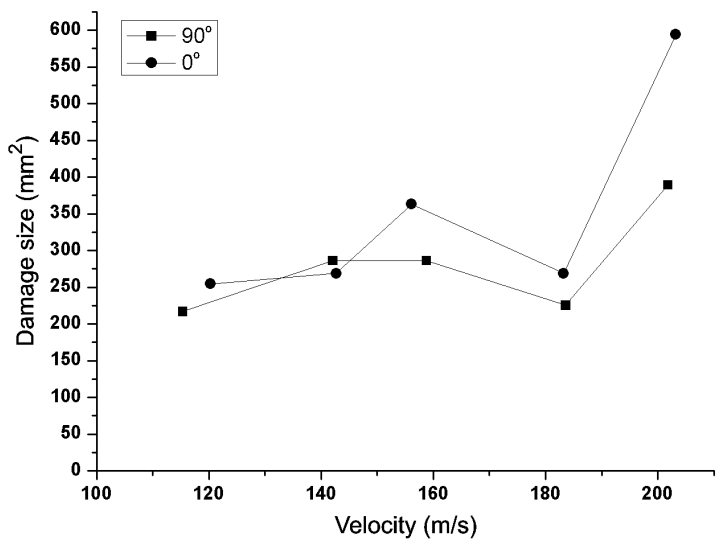

Fig. 9. Damage size of impact. 
Figure 10 shows that the maximum damage distance changes with speed for both impact styles. The damage region for the lateral impact is roughly semicircular, so the maximum damage distance for the lateral impact is much larger than that of the normal impact. This is true despite the fact that the damage size for the normal impact is slightly bigger than that of the lateral impact.

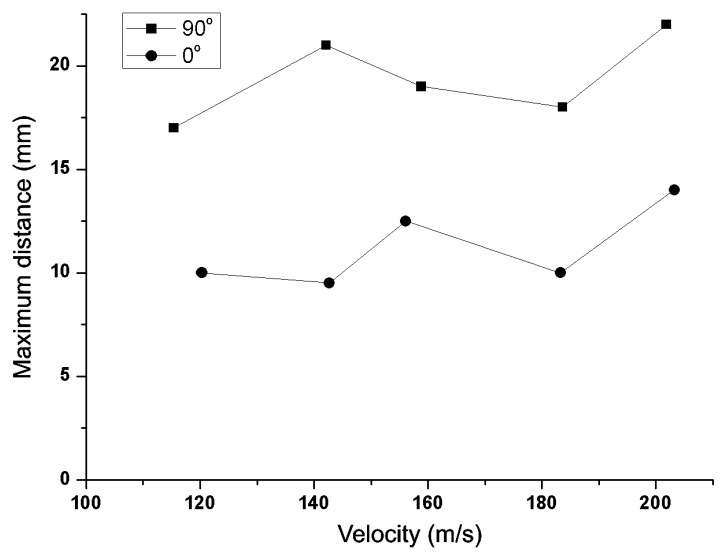

Fig. 10. Maximum damage distance of impact.

3. Numerical Simulation. Commercial finite element (FE) analysis software (ABAQUS/Explicit) was used to conduct dynamic FE analysis and simulate the damage process in the CFRP laminate. Five damage types were considered in the analysis: fiber tensile failure, fiber compression buckling, matrix cracking, matrix crushing, and delamination. Using 3D Hashin failure criteria, it was determined that the ply damage suffered fiber tensile failure, fiber compression buckling, matrix cracking, and matrix crushing. When a failure criterion was satisfied, the stress components that related to the failure mode were set to zero, as shown in Table 1 .

T a b 1 e 1

Stress Reduction for Damage Modes

\begin{tabular}{|c|c|}
\hline Damage mode & Stress reduction \\
\hline Fiber tensile failure & $\sigma_{11}=\sigma_{22}=\sigma_{33}=\sigma_{12}=\sigma_{23}=\sigma_{13}=0$ \\
\hline Fiber compression buckling & $\sigma_{11}=\sigma_{22}=\sigma_{33}=0$ \\
\hline Matrix cracking & $\sigma_{22}=\sigma_{12}=0$ \\
\hline Matrix crushing & $\sigma_{22}=0$ \\
\hline
\end{tabular}

Formulas (3)-(6) describe the 3D Hashin failure criteria. In these formulas, subscripts $i$ and $j$ denote stress direction, $S_{i j}$ denotes the shear strength of the corresponding direction, $X_{t}$ is the tensile strength of the fiber direction, $X_{c}$ is the compression strength of the fiber direction, $Y_{t}$ is the normal tensile strength of the fiber direction, and $Y_{c}$ is the normal compression strength of the fiber direction.

(i) Fiber tensile failure $\left(\sigma_{11} \geq 0\right)$

$$
f_{t}=\left(\frac{\sigma_{11}}{X_{t}}\right)^{2}+\left(\frac{\sigma_{12}}{S_{12}}\right)^{2}+\left(\frac{\sigma_{13}}{S_{13}}\right)^{2} \geq 1 ;
$$


(ii) fiber compression buckling $\left(\sigma_{11}<0\right)$

$$
f_{t}=\left(\frac{\sigma_{11}}{X_{c}}\right)^{2} \geq 1
$$

(iii) matrix cracking $\left(\sigma_{22}+\sigma_{33} \geq 0\right)$

$$
m_{t}=\left(\frac{\sigma_{22}+\sigma_{33}}{Y_{t}}\right)^{2}+\left(\frac{1}{S_{23}^{2}}\right)\left(\sigma_{23}^{2}-\sigma_{22} \sigma_{33}\right)+\left(\frac{\sigma_{12}}{S_{12}}\right)^{2}+\left(\frac{\sigma_{13}}{S_{13}}\right)^{2} \geq 1 ;
$$

(iv) matrix crushing $\left(\sigma_{22}+\sigma_{33}<0\right)$

$$
\begin{aligned}
m_{c}=\frac{1}{Y_{c}} & {\left[\left(\frac{Y_{c}}{2 S_{12}}\right)^{2}-1\right]\left(\sigma_{22}+\sigma_{33}\right)+\left(\frac{\sigma_{22}+\sigma_{33}}{2 S_{12}}\right)^{2}+\left(\frac{\sigma_{22}+\sigma_{33}}{2 S_{12}}\right)^{2}+} \\
& +\left(\frac{1}{S_{23}^{2}}\right)\left(\sigma_{23}^{2}-\sigma_{22} \sigma_{33}\right)+\left(\frac{\sigma_{12}}{S_{12}}\right)^{2}+\left(\frac{\sigma_{13}}{S_{13}}\right)^{2} \geq 1 .
\end{aligned}
$$

A cohesive element was employed to simulate delamination. A cohesive element is the cohesive zone model introduced between two brick elements; it generates the cohesive traction that resists the increase of the relative displacement between the two brick elements. If the relative displacement is very small, the cohesive element will behave as the penalty spring. However, if the traction is over the threshold value, the traction will gradually decrease to zero.

Figure 11 shows the numerical model used in this study. The stacking sequence was $\left[(45 / 0 /-45 / 90)_{4} / 0\right]_{S}$; the dimensions were $150 \times 45 \times 5 \mathrm{~mm}$, as with the specimen.

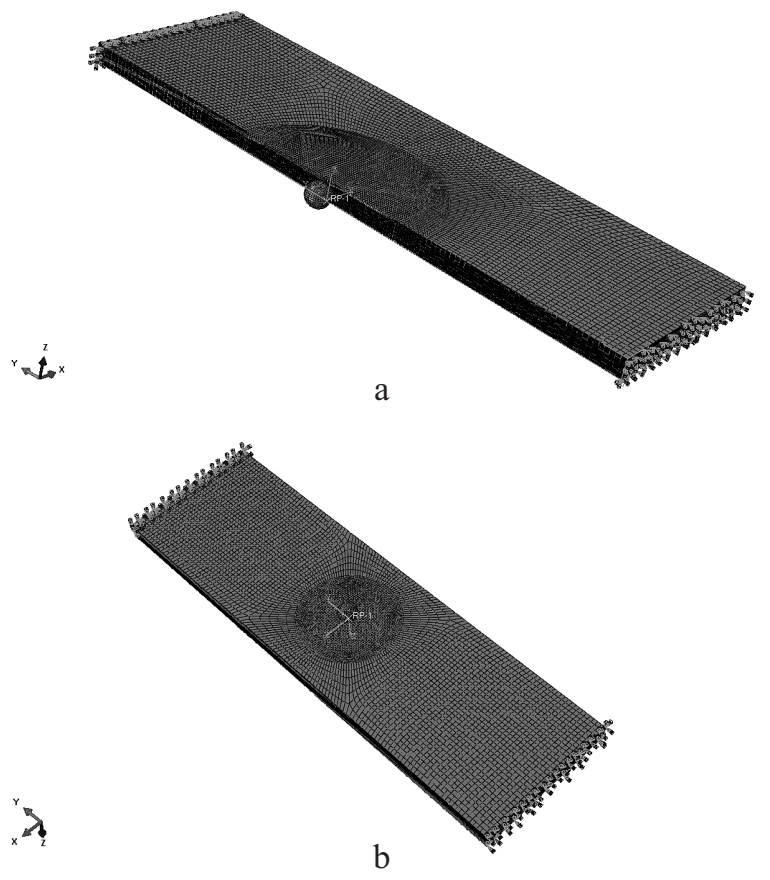

Fig. 11. Numerical model of lateral (a) and normal (b) impacts. 
Figure 12 is a numerical model of normal impact to contrast with this study, the simulation method as same as lateral impact. Eight linear reduced integration node elements were employed to express the laminate; one ply was modeled by one element. The model was fixed at both ends. A cohesive element was introduced between every two plies. The unit densities near the point of impact were denser than in other parts. The elements judged as fiber tensile failures were ignored.

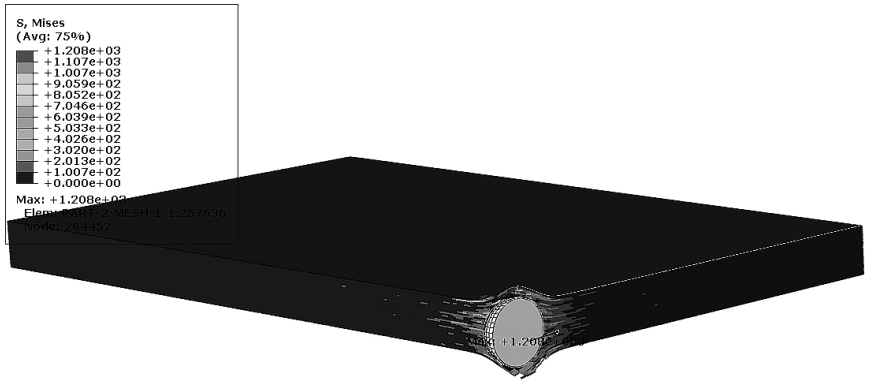

ODE: composite-impact-ex.odb Abaqus/Explicit 6.11-1 Thu Jan 08 20:33:21 GMT+08:00 2015

$\Gamma^{3 \times}$

Step: Step-1
Increment
Primary Var: $s$, Mises Step Time $=2.5004 \mathrm{E}-05$

Primary Var: 1 , Mises
Deforrmed Vart Weformation Scale Factor: $+\mathbf{1 . 0 0 0 e}+00$
Status Var: STATUS

a

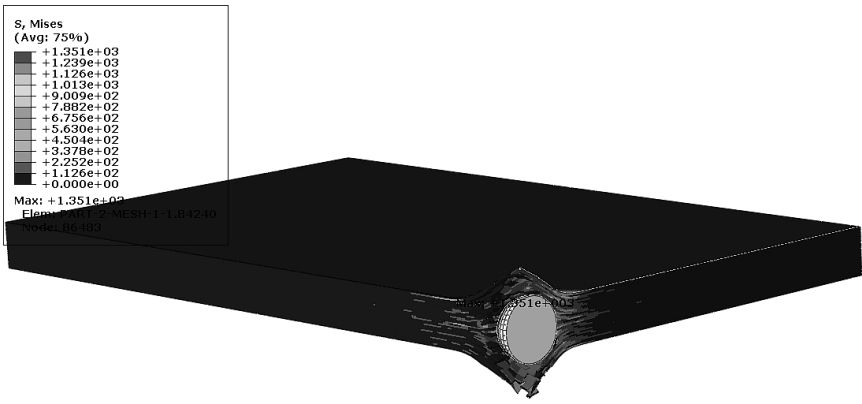

ODB: composite-impact-ex.odb Abaqus/Explicit 6.11-1 Thu Jan 08 20:33:21 GMT+08:00 2015

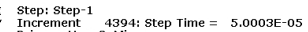

Primary Var: $S_{\text {s }}$ Mises
Deformed Var: $U$ Deformation Scale Factor: $+1.000 e+00$

$\mathrm{b}$

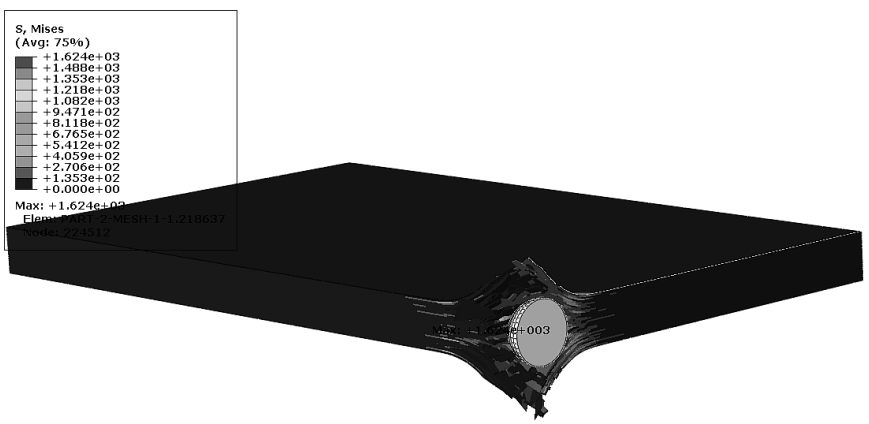

ODB: composite-impact-ex.odb Abaqus/Explicit 6,11-1 Thu Jan 08 20:33:21 GMT+08:00 2015

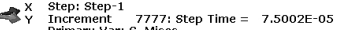

Increment
PPimary Var: S: Mises
Deformed Var: U Deformation Scale Factor: $+1.000 e+00$ 


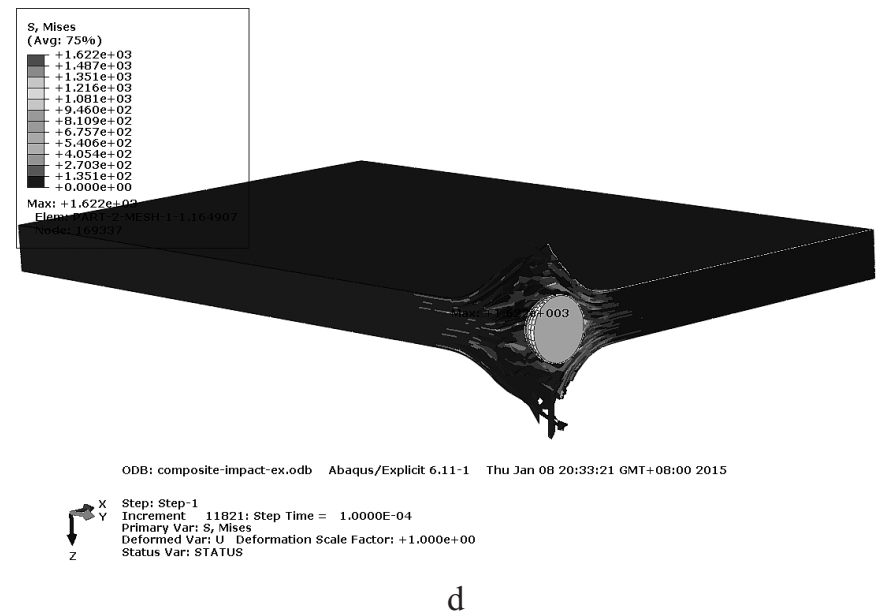

Fig. 12. Numerical nephogram of Mises stress of lateral impact: (a) $t=0.025 \mathrm{~ms}$; (b) $t=0.05 \mathrm{~ms}$; (c) $t=0.075 \mathrm{~ms}$; (d) $t=0.1 \mathrm{~ms}$.

The diameter of the modeled spherical projectile was $6 \mathrm{~mm}$ with a density of 7800 $\mathrm{kg} / \mathrm{m}^{3}$. It was modeled as a rigid surface, and the hard contacts were considered between the projectile and the laminates. Friction was not considered.

The formulation of fiber tensile failure, fiber compression buckling, matrix cracking, and matrix crushing were implemented using user subroutine Vumat; it used formula (7) to update the stress:

$$
\left\{\begin{array}{l}
\sigma_{11}^{n+1} \\
\sigma_{22}^{n+1} \\
\sigma_{33}^{n+1} \\
\sigma_{12}^{n+1} \\
\sigma_{23}^{n+1} \\
\sigma_{13}^{n+1}
\end{array}\right\}=\left\{\begin{array}{lllll}
C_{11} & C_{12} & C_{13} & & \\
C_{21} & C_{22} & C_{23} & & \\
C_{31} & C_{32} & C_{33} & & \\
& & C_{44} & \\
& & & C_{55} & \\
& & & & C_{66}
\end{array}\right\}\left\{\begin{array}{l}
\varepsilon_{11}^{\Delta} \\
\varepsilon_{22}^{\Delta} \\
\varepsilon_{33}^{\Delta} \\
\varepsilon_{12}^{\Delta} \\
\varepsilon_{23}^{\Delta} \\
\varepsilon_{13}^{\Delta}
\end{array}\right\}+\left\{\begin{array}{l}
\sigma_{11}^{n} \\
\sigma_{22}^{n} \\
\sigma_{33}^{n} \\
\sigma_{12}^{n} \\
\sigma_{23}^{n} \\
\sigma_{13}^{n}
\end{array}\right\} .
$$

A built-in cohesive element was used to simulate delamination. The initial velocity of the projectile was set to $200 \mathrm{~m} / \mathrm{s}$. Tables 2 and 3 show the material and cohesive properties.

Figure 12 shows the stress extension trend. Near the impact point, the projectile impact caused fiber failure and a crater. Extruding the outer ply projecting outward, the projections were symmetrical from top to bottom. It can be find that the stress extends far away from the impact point. Along with time growth, at plies of 0 and $90^{\circ}$, the stress propagation distances along the fiber direction are much longer than in other plies; this suggests that stress waves spread faster along the fiber direction.

Figure 13 shows that matrix cracking and delamination extruded from the impact point and the damage size increased with lateral impact time.

Figure 14 shows the matrix cracking and the delamination of normal impact. From the two pictures, it can be observed that the fiber failure happened only at the impact point. Matrix cracking had the largest damage type size; it extruded faster than delamination, but the delamination damage always happened with matrix cracking. In a normal impact, matrix cracking sizes decreased gradually along the thickness direction from top to bottom, but the delamination damage sizes increased gradually from top to bottom. The maximum 
Experimental and Numerical Analysis ...

delamination damage area is smaller than the matrix cracking area in the same ply. In lateral impacts, the maximum damage area for matrix cracking were the closed middle ply, the maximum damage area for delamination were the closed surfaces, and the damage size of the matrix cracking was also larger than the delamination damage size at the same ply.

$\mathrm{T}$ a b 1 e 2

\section{Material Properties}

\begin{tabular}{||c|c|c|c|c|c|c|c||}
\hline \hline$E_{1}, \mathrm{GPa}$ & $E_{2}, \mathrm{GPa}$ & $E_{3}, \mathrm{GPa}$ & $v_{12}$ & $v_{13}$ & $v_{23}$ & $G_{12}, \mathrm{GPa}$ & $G_{13}, \mathrm{GPa}$ \\
\hline 135 & 8.8 & 8.8 & 0.33 & 0.33 & 0.45 & 4.47 & 4.47 \\
\hline$G_{23}, \mathrm{GPa}$ & $X_{t}, \mathrm{MPa}$ & $X_{c}, \mathrm{MPa}$ & $Y_{t}, \mathrm{MPa}$ & $Y_{c}, \mathrm{MPa}$ & $S_{12}, \mathrm{MPa}$ & $S_{13}, \mathrm{MPa}$ & $S_{23}, \mathrm{MPa}$ \\
\hline 3.4 & 1548 & 1226 & 55.5 & 218 & 89.9 & 110.9 & 110.9 \\
\hline
\end{tabular}

$\mathrm{T}$ a b 1 e 3

\section{Cohesive Properties}

\begin{tabular}{|c|c|c|c|c|c|c|c|c|}
\hline $\begin{array}{c}E, \\
\mathrm{GPa}\end{array}$ & $\begin{array}{c}G_{1}, \\
\mathrm{GPa}\end{array}$ & $\begin{array}{c}G_{2}, \\
\mathrm{GPa}\end{array}$ & $\begin{array}{c}S_{n}, \\
\mathrm{MPa}\end{array}$ & $\begin{array}{c}S_{s}, \\
\mathrm{MPa}\end{array}$ & $\begin{array}{c}S_{t}, \\
\mathrm{MPa}\end{array}$ & $\begin{array}{c}G_{n c}, \\
\mathrm{~J} / \mathrm{m}^{2}\end{array}$ & $\begin{array}{c}G_{s c}, \\
\mathrm{~J} / \mathrm{m}^{2}\end{array}$ & $\begin{array}{c}G_{t c}, \\
\mathrm{~J} / \mathrm{m}^{2}\end{array}$ \\
\hline 8.8 & 3.4 & 3.4 & 55.5 & 89.9 & 89.9 & 252 & 665 & 665 \\
\hline
\end{tabular}

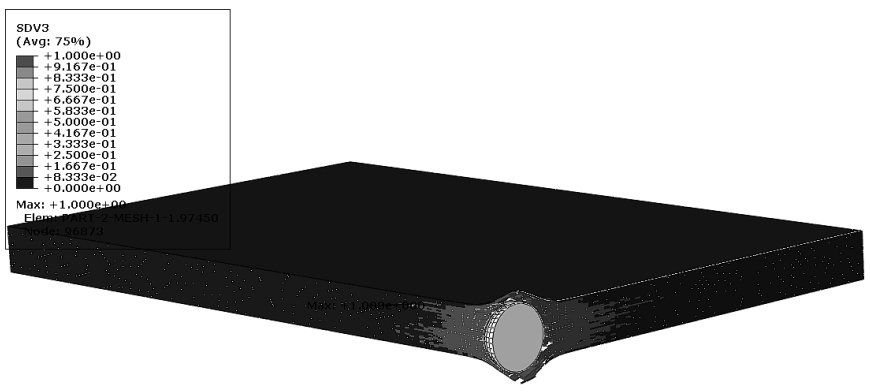

ODB: composite-impact-ex.0db Abagus/Explicit 6,11-1 Thu Jan 08 20:33:21 GMT+08:00 2015

Step: Step-1
Increment
$1663:$ Step Time $=2.5004 \mathrm{E}-05$

Primary Var: SDV 3 ,
Deformed Var: 4 Deformation Scale Factor: $+1.000 e+00$

a

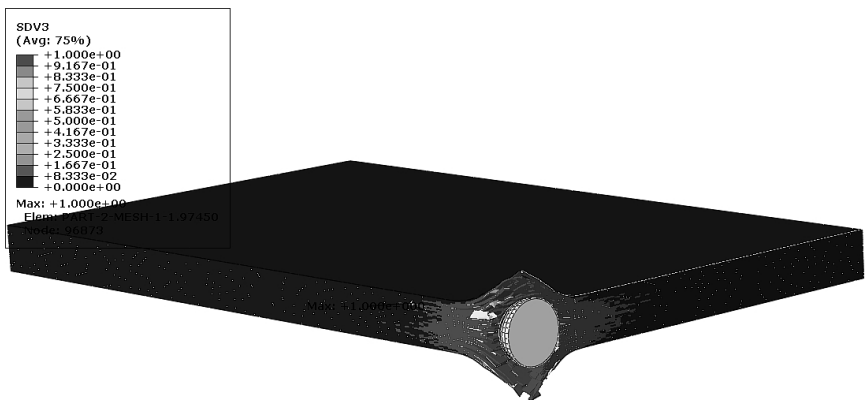

ODB: composite-impact-ex,odb Abaqus/Explicit 6,11-1 Thu Jan 08 20:33:21 GMT+08:00 2015

Step: Step-1
Increment
4394: Step Time $=5.0003 E-05$

Primary Var: SDV 3 (a) 


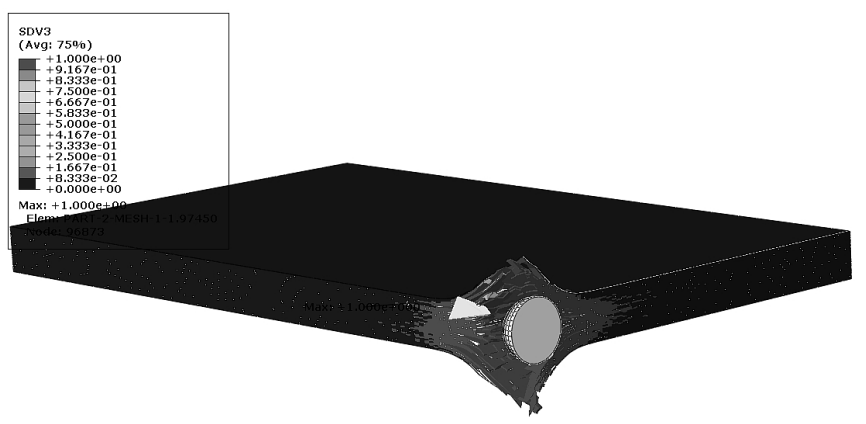

ODB: composite-impact-ex.odb Abaqus/Explicit 6.11-1 Thu Jan 08 20:33:21 GMT+08:00 2015

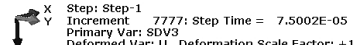

Primary Vari sDV3
Deformed var:
Status Veformation Scale Factor: $+\mathbf{1 . 0 0 0 e + 0 0}$

C

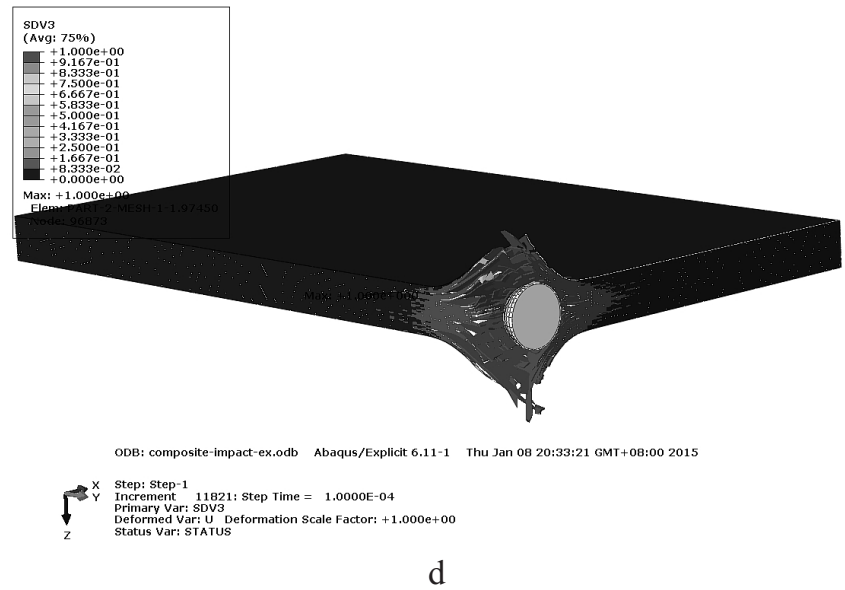

Fig. 13. Numerical nephogram of matrix cracking and delamination of lateral impact: (a) $t=0.025 \mathrm{~ms}$; (b) $t=0.05 \mathrm{~ms}$; (c) $t=0.075 \mathrm{~ms}$; (d) $t=0.1 \mathrm{~ms}$.

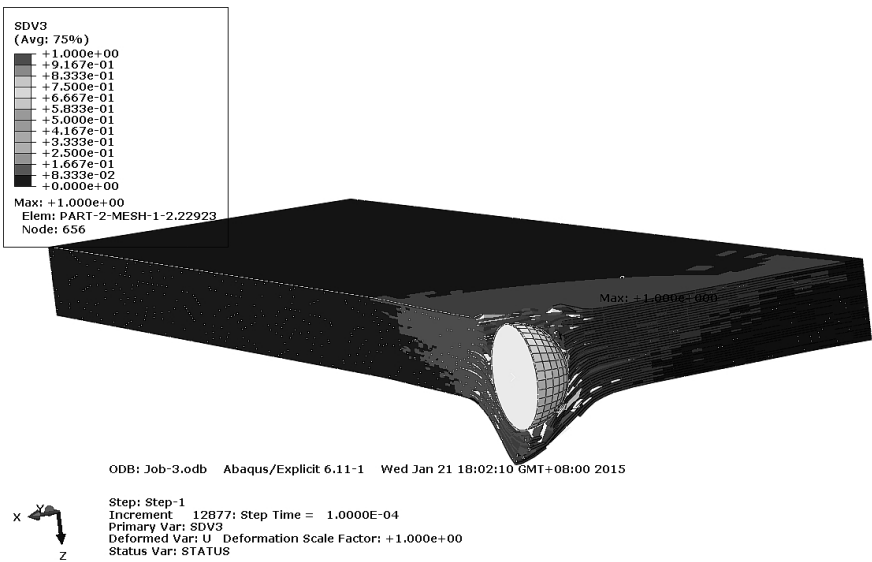

Fig. 14. Numerical nephogram of matrix cracking and delamination of normal impact.

Figures 13 and 14 demonstrate that cracks were bigger if the region was close to the impact point, regardless of the impact type and damage size. Damage areas for delamination 
increased gradually from the impact point to the opposite surface, which is consistent with findings [28]. Delamination and fiber failure always happened in conjunction with matrix cracking. The damage size of matrix cracking was always larger than the delamination damage size at the same ply.

\section{Conclusions}

1. Damage area shapes for normal and lateral impacts varied. The normal impact damage region shape was roughly circular around the impact point, and the damage size increased gradually along the thickness direction from top to bottom. The lateral impact damage region shape was roughly semicircular around the impact point and symmetrical from top to bottom. The damage area was closer to the surface as speed increased.

2. The normal impact damage size was slightly larger than the lateral-impact damage size, but the maximum damage distance for the lateral impact was much larger than that of the normal impact. It is surmised that the response time of the lateral-impact load was longer than the normal-impact load response time, and the longitudinal stress wave spread faster than the transverse wave, so the stress waves spread farther.

3. The numerical model, which is based on the FE model, includes a cohesive element. The 3D Hashin criteria can accurately simulate the impact process. The simulation shows a good correlation with the experimental results.

1. Y. Zhang, Study on Impact Damage Prediction in Fiber Reinforced Composite Laminate Structures, Ph.D. Thesis, Shanghai Jiao Tong University (2007).

2. L. C. Yu, Numerical Analysis Technology and Application Research of Bird Impact on Composites Structure, Master's Thesis, Nanjing University of Aeronautics and Astronautics (2008).

3. D. A. Smith, Necessity of Retractable Inlet Screens in Axial Flow Turbojet Engine Powered Aircraft, Tech. Note WCLP 53-41 (1953).

4. A. F. Storace, Foreign Object Impact Design Criteria, AFAPL-TR-78-81 (1982).

5. R. S. Bertke, Materials Screening Tests of the FOD Impact Design Technology Program. Task IV C (1982).

6. T. Nicholas, J. P. Barber, and R. S. Bertke, "Impact damage on titianium leading edges from small hard objests," Exp. Mech., 20, No. 10, 357-364 (1980).

7. S. M. Wiederhorn and B. R. Lawn, "Strength degradation of glass resulting from impact with spheres," J. Am. Ceram. Soc., 60, No. 9-10, 451-458 (1977).

8. S. M. Wiederhorn and B. R. Lawn, "Strength degradation of glass impact with sharp particles: I, annealed surfaces," J. Am. Ceram. Soc., 62, No. 1-2, 66-70 (1979).

9. K. Breder, G. de Portu, J. E. Ritter, and D. D. Fabbriche, "Erosion damage and strength degradation of zirconia-toughened alumina," J. Am. Ceram. Soc., 71, No. 9, 770-775 (1988).

10. J. E. Ritter, S. R. Choi, K. Jakus, et al., "Effect of microstructure on the erosion and impact damage of sintered silicon nitride," J. Mater. Sci., 26, 5543-5546 (1991).

11. Y. Akimune, Y. Katano, and K. Matoba, "Spherical-impact damage and strength degradation in silicon nitrides for automobile turbocharger rotors," J. Am. Ceram. Soc., 72, No. 8, 1422-1428 (1989).

12. D. A. Shockey, D. J. Rowcliff, K. C. Dao, and L. Seaman, "Particle impact damage in silicon nitride," J. Am. Ceram. Soc., 73, No. 6, 1613-1619 (1990).

13. C. G. Knight, M. V. Swain, and M. M. Chaudhri, "Impact of small steel spheres on glass surfaces," J. Mater. Sci., 12, 1573-1586 (1977). 
14. A. M. Rajendran and J. L. Kroupa, "Impact design model for ceramic materials," J. Appl. Phys., 66, No. 8, 3560-3565 (1989).

15. B. Bachtel, Foreign Object Debris and Damage Prevention, http://www.boeing.com/ commercial/aeromagazine/aero_01/textonly/s01 txt.html. Retrieved on 02 August 2009.

16. W. J. Cantwell and J. Morton, "Detection of impact damage in CFRP laminates," Compos. Struct., 3, 241-257 (1985).

17. W. J. Cantwell and J. Morton, "Comparison of low and high velocity impact response of CFRP," Composites, 20, No. 6, 545-551 (1989).

18. W. J. Cantwell and J. Morton, "Impact perforation of carbon fibre reinforced plastic," Compos. Sci. Technol., 38, No. 2, 119-141 (1990).

19. Y. Tanabe, M. Aoki, K. Fujii, et al., "Fracture behavior of CFRPs impacted by relatively high-velocity steel sphere," Int. J. Impact Eng., 28, 627-642 (2003).

20. A. F. Johnson and N. Pentecôte, "Modelling impact damage in double-walled composite structures," in: Computational Plasticity: Fundamentals and Applications (Proc. of the 8th Int. Conf. on Computational Plasticity (COMPLAS'05), Sept. 5-9, 2005, Barcelona, Spain), Part 1, Barcelona (2005), pp. 517-520.

21. P. J. Hazell, G. Kister, C. Stennett, et al., "Normal and oblique penetration of woven CFRP laminates by a high velocity steel sphere," Composites Part A: Appl. Sci. Manuf., 39, No. 5, 866-874 (2008).

22. P. J. Hazell, A. Cowie, G. Kister, et al., "Penetration of a woven CFRP laminate by a high velocity steel sphere impacting at velocities up to $1875 \mathrm{~m} / \mathrm{s}$," Int. J. Impact Eng., 36, No. 9, 1136-1142 (2009).

23. G. J. Appleby-Thomas, P. J. Hazell, and G. Dahini, "On the response of two commercially important CFRP structures to multiple ice impacts," Compos. Struct., 93, 2619-2627 (2011).

24. A. Shimamoto, R. Kubota, and K. Takayama, "High-velocity impact characteristic of carbon fiber reinforced plastic composite at low temperature," J. Strain Anal., 47, 471-479 (2012).

25. J. López-Puente, R. Zaera, and C. Navarro, "Experimental and numerical analysis of normal and oblique ballistic impacts on thin carbon/epoxy woven laminates," Composites Part A: Appl. Sci. Manuf., 39, No. 2, 374-387 (2008).

26. J. Pernas-Sánchez, J. A. Artero-Guerrero, D. Varas, and J. López-Puente, "Experimental analysis of normal and oblique high velocity impacts on carbon/epoxy tape laminates," Composites Part A: Appl. Sci. Manuf., 60, 24-31 (2014).

27. G. Z. Quan, D. S. Wu, and G. S. Li, "The investigation on frontal and lateral impact resistances of E glass fiber epoxy resin matrix composite," Mater. Rev., 18, 67-70 (2013).

28. Y. M. Cheng, The Study of Damage Resistance and Damage Tolerance of Composite Laminates, Master's Thesis, Northwestern Polytechnical University (2010). 